Volume 10, Nomor 1, Mei 2018, pp 30-40 Copyright (C) 2017 Jurnal Akuntansi Maranatha, Program Studi Akuntansi, Fakultas Ekonomi, Universitas Kristen Maranatha. ISSN 2085-8698 | e-ISSN 2598-4977. http://journal.maranatha.edu

\title{
Aplikasi Metode EOQ Dalam Pengendalian Persediaan Bahan Baku PT X
}

\author{
Mellisa Andiana \\ Fakultas Ekonomi Program Studi Magister Manajemen \\ Universitas Katolik Parahyangan \\ (Jln. Merdeka No. 30, Bandung) \\ mellisa.andiana@yahoo.com \\ Gandhi Pawitan \\ Fakultas Ekonomi Program Studi Magister Manajemen \\ Universitas Katolik Parahyangan \\ (Jln. Merdeka No. 30, Bandung) \\ gandhi_p@unpar.ac.id
}

\begin{abstract}
Tujuan dari penelitian ini untuk mengetahui dan menganalisis seberapa efisien bahan baku yang dikendalikan dalam proses produksi di PT X untuk memenuhi permintaan konsumen. Penelitian ini dilakukan dengan menggunakan analisa deskriptif untuk menggambarkan atau menguraikan data yang akan diteliti kemudian diolah menggunakan perhitungan EOQ. Data yang akan diteliti adalah data permintaan dan data produksi.Data tersebut diambil berdasarkan melakukan survey ke lokasi dan juga wawancara dengan pemilik PT X. Setelah data tersebut didapatkan kemudian dibuat analisis dengan menggunakan metode EOQ. Berdasarkan hasil penelitian, diperoleh bahwa proses produksi di PT X yang dilakukan memiliki hasil yang baik karena seluruh pekerjaan dilakukan saling berurutan dan dapat selesai sesuai dengan jadwal yang telah disepakati. Persediaan bahan baku yang telah dihitung dengan menggunakan metode EOQ menghasilkan jumlah ekonomis. Perusahaan dapat menghemat biaya dari setiap biaya aktual bahan baku sehingga dapat mengetahui jumlah optimal bahan baku yang dapat dipesan dalam periode tertentu dan biaya yang harus dikeluarkan.
\end{abstract}

Keywords: Economic Order Quantity (EOQ), Persediaan Bahan Baku 



\section{Pendahuluan}

Persaingan ekonomi dalam dunia usaha, berkembang dengan sangat pesat di Indonesia, sehingga menuntut berbagi industri untuk dapat bekerja lebih baik agar dapat terus bertahan. Persaingan dilakukan berdasarkan laba yang diperoleh, jumlah pelanggan, menentukan strategi, dan kegiatan produksi agar perusahaan dapat berkembang menjadi lebih baik lagi. Proses produksi dalam suatu perusahaan dapat dipengaruhi berbagai faktor yang ada di dalam perusahaan itu sendiri, seperti faktor teknologi, modal, penjadwalan, dan persediaan bahan baku. Perusahaan pun dalam mencapai tujuan organisasinya akan memaksimalkan kinerjanya dalam setiap bidang.

Berdasarkan data Kementrian Perindustrian, pasar industri percetakan di dalam negeri terus tumbuh dan menguat. Hingga saat ini terdapat minimal 35 ribu pelaku industri percetakan dengan segmen pasar lebih dari Rp 130 triliun setiap tahun. Para pelaku usaha di industri grafika optimistis industri berbasis percetakan, penerbitan dan converting bisa tumbuh 5,3\% atau lebih baik dibandingkan dengan proyeksi sebelumnya sebesar 4,7\%. Menurut Jimmy Junianto (Ketua APKIAsosiasi Pulp dan Kertas Indonesia) besarnya pertumbuhan industri grafika tak lepas dari tingginya konsumsi kertas di dalam negeri. Berdasarkan data Asosiasi Pulp dan Kertas Indonesia (APKI), kapasitas industri kertas mencapai 12,5 juta ton per tahun dengan konsumsi domestik mencapai $60 \%-65 \%$ per tahun. Jika dilihat dari konsumsi domestik, pertumbuhan industri grafika kemungkinan bisa lebih tinggi dibandingkan dengan proyeksi awal sebesar $4,7 \%$. Ini terlihat dari data impor mesin cetak industri grafika yang naik $40 \%$ menjadi US\$392 juta dibandingkan dengan impor pada 2010 yang hanya US\$280 juta.

(Sumber: berita Kementrian Perindustrian RI)
Meningkatnya industri ini, mengakibatkan persaingan bisnis pun semakin ketat apalagi di perburuk dengan kemajuan teknologi yang mengakibatkan banyak bisnis gulung tikar karena tidak mampu menghadapi persaingan. Hal ini dapat berdampak negatif bagi para pengusaha percetakan. Agar perusahaan dapat mampu bersaing, perlu adanya inovasi terhadap usaha yang dijalani baik dari segi produk, pelayanan atau bahkan menciptakan strategi yang berbeda agar perusahaan mampu bertahan.

Salah satu strategi yang dapat membantu perusahaan adalah dengan melakukan pengelolaan persediaan bahan baku yang tepat, karena jumlah persediaan akan berpengaruh terhadap kelancaran proses produksi agar dapat menjadi efisien bagi perusahaan. Pada dasarnya semua perusahaan mengadakan perencanaan dan pengendalian bahan baku dengan tujuan biaya yang minimum dan laba yang maksimum sesuai dengan waktu tertentu. Fungsi utama perusahaan mempunyai persediaan adalah agar perusahaan dapat membeli dan membuat produk dalam jumlah yang ekonomis (Sofyan: 2013). Agar biaya persediaan dapat menjadi lebih efektif perlu dilakukan manajemen persediaan yang dapat membantu perusahaan dalam mengontrol kelebihan atau kekurangan persediaan bahan baku. Pengelolaan bahan baku yang baik dan tepat akan membantu kelancaran proses produksi sehingga pesanan konsumen dapat dipenuhi dengan waktu yang relatif lebih cepat. Alasan lainnya adalah untuk berjaga-jaga apabila sewaktu-waktu bahan baku mengalami kelangkaan atau adanya lonjakan harga yang signifikan.

Dalam manajemen persediaan bahan baku, diperlukan metode EOQ. Selain itu, perusahaan juga perlu untuk menentukan waktu pemesanan kembali (Reorder Point - ROP) agar pembelian bahan baku menjadi lebih ekonomis dan optimal. PT X adalah salah satu perusahaan yang bergerak di bidang jasa cetak packaging dan printing. Produk- 
produk yang dihasilkan PT X seperti hang tag, stiker makanan, inner dan outer kemasan obat, dus makanan, stiker, etiket, dan brosur untuk obat, shopping bag, amplop, kop surat, kartu nama, undangan, buku, dan berbagai hal yang berhubungan dengan kertas. Namun untuk produk kemasan obat dan shopping bag yang menjadi produk utama perusahaan ini. Adapun jumlah data pesanan yang dapat dilihat pada tabel berikut ini:

\section{Tabel 1}

Data Produksi PT X (dalam ribuan unit)

\begin{tabular}{|c|c|c|c|c|c|c|c|c|c|c|}
\hline \multicolumn{6}{|c|}{ Kemassan Obat } & \multicolumn{5}{|c|}{ Shopping Bagg } \\
\hline & 1 & 2 & 3 & 4 & Total & 1 & 2 & 3 & 4 & Total \\
\hline Data! & 75 & 75 & 80 & 70 & 300 & 10 & 12 & 12 & 14 & 48 \\
\hline Data? & 10 & 75 & 80 & 85 & 310 & 12 & 14 & 12 & 14 & 52 \\
\hline Data 3 & 90 & 100 & 100 & 100 & 390 & 14 & 14 & 14 & 14 & 36 \\
\hline & & & & & 1.000 & & & & & 156 \\
\hline
\end{tabular}

(Sumber : data perusahaan)

Data diatas dapat dilihat bahwa adanya peningkatan untuk produk kemasan obat dan shopping bag. Sehingga perlu dilakukan pengelolaan bahan baku agar proses produksi tidak terganggu dan kebutuhan konsumen dapat terpenuhi sesuai waktu yang telah disepakati. Berdasarkan latar belakang tersebut, maka tujuan penelitian ini adalah untuk mengetahui seberapa efisien bahan baku yang digunakan dalam proses produksi dan mengetahui pengendalian persediaan bahan baku PT $\mathrm{X}$ dalam memenuhi permintaan konsumen.

\section{Kerangka Teoritis}

Proses produksi terbagi menjadi 2 jenis yaitu proses produksi terus-menerus (continuous processes) yaitu memproduksi produk dalam jangka waktu yang panjang tanpa mengalami perubahan, maka prosesnya menjadi terus-menerus selama jenis produk yang sama dikerjakan. Proses produksi terus menerus memiliki produk dengan volume besar tetapi varietasnya sedikit. Yang kedua proses produksi terputus-putus (intermittent process) yaitu memproduksi barang dalam jangka waktu yang pendek, dan kemudian dirubah atau dipersiapkan kembali untuk memproduksi produk lain, sehingga prosesnya terputus-putus tergantung dari produk yang dikerjakan. Proses terputus ini memiliki produk dengan volume rendah namun varietasnya banyak. Proses produksi adalah cara metode dan teknik untuk menciptakan atau menambah kegunaan suatu barang atau jasa dengan menggunakan sumbersumber (tenaga kerja, mesin, bahanbahan dan dana) yang ada. (Assauri 1993:97).

\section{Persediaan}

Persediaan (inventory) adalah stock atau simpanan barang-barang yang disimpan perusahaan dalam persediaan yang berhubungan dengan bisnis yang dilakukan (Stevenson dan Chuong, 2014: 180). Persediaan mempunyai sejumlah fungsi menurut Stevenson dan Chuong (2014: 181), yang paling 
penting adalah untuk memenuhi permintaan pelanggan yang diperkirakan, memperlancar persyaratan produksi, memisahkan operasi, perlindungan terhadap kehabisan persediaan, mengambil keuntungan dari siklus pesanan, melindungi dari peningkatan harga, memungkinkan operasi, dan untuk mengambil keuntungan dari diskon kuantitas. Adapun Persediaan (inventory) adalah barang atau bahan yang merupakan salah satu Berdasarkan kekayaan organisasi yang disimpan dalam antisipasinya terhadap pemenuhan permintaan (Handoko, 2011:333).

\section{Economic Order Quantity (EOQ)}

Economic Order Quantity adalah salah satu metode yang digunakan dalam penentuan jumlah kuantitas pemesanaan yang optimal (Syamsuddin, 2011:294). Model kuantitas pesanan ekonomis (Economic Order Quantity-EOQ) adalah salah satu teknik kontrol persediaan yang meminimalkan biaya total dari pemesanan dan penyimpanan (Heizer dan Render. 2005). Asumsi EOQ adalah

1. Jumlah permintaan diketahui, konstan, dan independen

2. Waktu tunggu yakni waktu antara pemesanan dan penerimaan pesanan diketahui dan konstan

3. Penerimaan persediaan bersifat instan dan selesai seluruhnya.

4. Tidak tersedia diskon kuantitas

5. Biaya variabel hanya biaya untuk menyiapkan atau melakukan pemesanan dan biaya menyimpan persediaan dalam waktu tertentu.

6. Kehabisan persediaan dapat sepenuhnya dihindari jika pemesanan dilakukan pada tepat waktu.

Tujuan EOQ (Economic Order Quantity) adalah untuk menentukan jumlah ekonomis setiap kali pemesanan sehingga meminimalisasi biaya total persediaan.

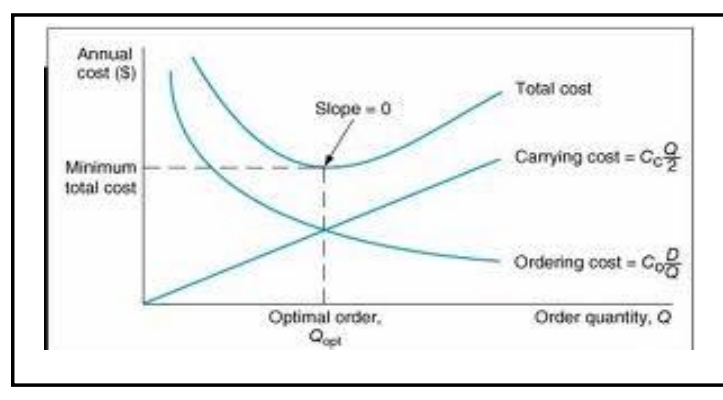

Gambar 1

Grafik Biaya Total Sebagai Fungsi Dari

Kuantitas Pesanan

Dari gambar diatas, biaya total merupakan penjumlahan 2 komponen biaya, yaitu biaya penyimpanan dan biaya pemesanan. Sehingga jarak kurva total cost pada setiap titik Q merupakan hasil penjumlahan jarak kedua kurva komponen biaya tersebut secara tegak lurus.

Biaya yang paling signifikan adalah biaya pemesanan dan biaya penyimpanan sedangkan untuk biaya persediaan sendiri sifatnya konstan. Jadi, jika biaya pemesanan dan biaya penyimpanan diminimalkan, maka akan meminimalkan biaya total. Seiring dengan meningkatnya kuantitas yang dipesan, jumlah pemesanan akan menurun. Namun dengan meningkatnya kuantitas pesanan, biaya penyimpanan akan meningkat karena jumlah persediaan rata-rata yang perlu diperhatikan menjadi lebih banyak. 


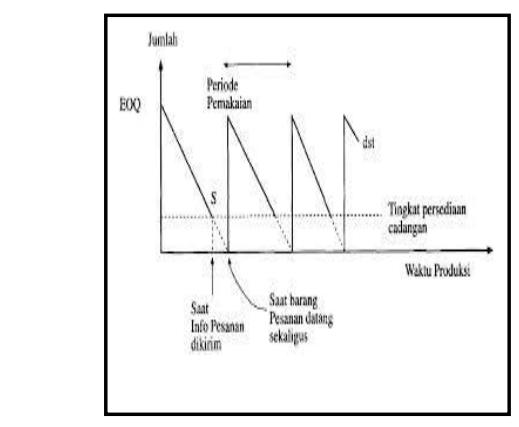

\section{Grafik Penggunaan Persediaan Dalam Waktu Tertentu}

Dalam grafik di atas, dapat dilihat bahwa grafik penggunaan persediaan terhadap waktu memiliki bentuk seperti gergaji, artinya adanya fluktuasi yang konstan. Tingkat persediaan meningkat saat pesanan tiba. Karena permintaan bersifat konstan sepanjang waktu, persediaan menurun pada laju yang sama sepanjang waktu. Setiap kali tingkat persediaan mencapai titik 0, pesanan baru dibuat serta diterima. Proses ini berlanjut sepanjang waktu. Rumusan EOQ :

$\mathrm{EOQ}=\sqrt{\frac{2 D S}{H}}$

Keterangan :

$\mathrm{D}$ : permintaan barang selama satu periode

$\mathrm{S}$ : biaya pesanan per order

$\mathrm{H}$ : biaya simpan per unit

Titik Pemesanan Ulang (ROP-Reorder Point)

Assauri (1993:234) menyatakan bahwa titik pemesanan ulang atau reorder point adalah suatu sistem atau cara pemesanan bahan, dimana pesanan dilakukan apabila persediaan yang ada telah mencapai suatu atau tingkat tertentu. Dengan reorder point sistem, dapat menentukan jumlah persediaan pada tingkat tertentu yang merupakan batas waktu dilakukannya pemesanan yang disebut order point atau reorder point.

Rumus ROP = lead time $\mathrm{x}$ kebutuhan rata-rata harian) + safety stock

Keterangan :

Safety stock: $\quad$ pemakaian maximal pemakaian rata-rata

Kebutuhan rata-rata harian =

$\frac{D}{\text { jumlah harikerja }}$

\section{Safety Stock}

Assauri (1993:242) menyatakan pengertian safety stock adalah persediaan tambahan yang diadakan untuk melindungi atau menjaga kemungkinan terjadinya kekurangan bahan (stock-out). Stock-out dapat terjadi karena penggunaan bahan baku yang lebih besar dari pada prakiraan semula, atau keterlambatan dalam penerimaan bahan baku yang dipesan. Dengan begitu perusahaan membutuhkan persediaan pengaman untuk menghindari stock-out. Namun persediaan pengaman ini tentu saja membutuhkan biaya, sehingga perusahaan perlu menghitung persediaan pengaman yang diperlukan dengan jumlah yang tepat agar tidak menjadi beban.

\section{Metode Penelitian}

Penelitian ini merupakan penelitian studi kasus, yaitu dengan melihat langsung ke perusahaan permasalahan apa yang sedang terjadi dan membantu memecahkan permasalahan tersebut berdasarkan teori yang sudah ada. Metode yang digunakan dalam penelitian ini adalah analisis deskriptif. Tujuan pemilihan metode deskriptif ini untuk menggambarkan atau menguraikan data yang akan diteliti kemudian diolah menggunakan perhitungan EOQ. Data yang akan diteliti adalah data permintaan, data produksi. 
Pertama-tama melakukan wawancara dengan pemilik percetakan untuk mengetahui secara garis besar mengenai perusahaan dan menganalisis masalah apa yang menjadi kendala. Selanjutnya melihat permasalahan mengenai penggunaan bahan baku pada percetakan tersebut apakah sudah efektif atau belum.

Tahap selanjutnya mengumpulkan data yang dibutuhkan seperti data jumlah produksi dan permintaan konsumen. Dan dari data yang telah didapat peneliti akan menganalisis dengan menggunakan metode EOQ, safety stock, reorder point.

\section{Hasil Penelitian dan Pembahasan}

Pada umumnya perusahaan telah memiliki jadwal pengerjaan pesanan dengan baik sesuai dengan waktu yang telah di disepakati dengan konsumen. Namun masalah yang perlu diantisipasi adalah bagaimana cara perusahaan dalam mengendalikan persediaan bahan bakunya. Ada banyak faktor yang dapat menyebabkan terjadinya keterlambatan penyelesaian pesanan, seperti:

1. Mesin

Proses produksi sebagian besar dilakukan dengan menggunakan mesin. Mesin yang ada di PT X hampir setiap hari beroperasi. Maka perawatan dan pemeliharaan mesin pun perlu diperhatikan sehingga tidak menghambat proses produksi. Jika mesin tidak mendapatkan pemeliharaan secara rutin, mesin akan mengalami kerusakan dan akan terjadi keterlambatan dalam mengerjakan pesanan konsumen.

2. Supplier bahan baku

PT X membutuhkan supplier dalam memenuhi kebutuhannya. Supplier yang dipilih harus dapat diajak bekerja sama dengan baik agar kebutuhan produksi dapat terpenuhi. Jika tidak perusahaan akan mengalami kendala seperti harga bahan baku yang dipatok terlalu mahal yang mengakibatkan harga produksi menjadi meningkat dan konsumen merasa terbebani, kemudian waktu pengiriman yang tidak sesuai dengan jadwal yang telah disepakati sehingga adanya keterlambatan proses produksi.

3. Tenaga kerja

Tenaga kerja yang kurang termotivasi atau memiliki kinerja yang kurang baik seperti, mengulur-ulur waktu bekerja,tidak teliti dan bertanggung jawab terhadap pekerjaanya akan berpengaruh juga terhadap terlambatnya proses produksi. Maka dari itu, para tenaga kerja perlu dimotivasi agar kinerja pun dapat meningkat, seperti diberi bonus, gaji yang sesuai dan suasana kerja dibuat nyaman.

4. Bahan baku

PT X merupakan industri di bidang manufaktur yang memproduksi bahan mentah menjadi barang jadi, yang tentu saja membutuhkan bahan baku sebagai modal utama. Bahan baku haruslah memiliki kualitas yang baik agar konsumen dapat merasa puas dengan barang yang dihasilkan. hambatan yang dapat menghambat proses produksi adalah kelangkaan bahan baku. Maka perusahaan perlu menyiapkan stok pengaman agar saat bahan baku mengalami kelangkaan atau adanya kenaikan permintaan, perusahaan masih dapat berproduksi. Bahan baku yang digunakan dalam percetakan sangat bervariasi, sehingga pengelolaan persediaan bahan baku merupakan satu aktivitas yang vital.

Penelitian ini akan menyoroti faktor bahan baku, yaitu dalam hal pengendalian persediaaan bahan baku.

\section{Persediaan Bahan Baku dan Pengendaliannya}

Dalam menyimpan persediaan bahan bakunya, PT X memiliki gudang sendiri dengan alasan agar bahan-bahan yang dibutuhkan saat produksi dapat cepat 
diambil dan digunakan sehingga waktu pengerjaan pun menjadi efektif. PT $X$ memiliki persediaan berupa bahan baku utama dan persediaan bahan baku penolong yang akan diolah menjadi barang jadi. Dalam mengendalikan persediaan bahan baku tersebut memerlukan biaya seperti biaya penyimpanan dan biaya pemesanan, sehingga jumlahnya pun perlu diperhitungkan agar tidak merugikan perusahaan.

Metode yang dapat membantu perhitungan tersebut adalah metode Economic Order Quantity (EOQ). Metode ini akan membantu menghitung jumlah bahan baku yang akan dipesan dengan nilai yang paling ekonomis.Ada dua produk yang akan diteliti, yaitu kemasan obat dan shopping bag. Kedua produk ini membutuhkan bahan baku utama untuk diproses, untuk kemasan obat bahan baku utama yang dibutuhkan adalah karton dan tinta, sedangkan untuk shopping bag bahan baku utamanya adalah kertas dan tinta.

Dalam melakukan perhitungan dengan metode EOQ (Economic Order Quantity) diperlukan data permintaan seperti pada tabel berikut:

\begin{tabular}{|l|l|l|}
\hline Bahan Baku & Nilai Max & Nilai Min \\
\hline Karton & 70.200 & 54.000 \\
\hline Tinta B\&W & 105 & 81 \\
\hline $\begin{array}{l}\text { Tinta Full } \\
\text { color }\end{array}$ & 210 & 162 \\
\hline Kertas & 10.800 & 9.600 \\
\hline Tinta B\&W & 17 & 16 \\
\hline $\begin{array}{l}\text { Tinta Full } \\
\text { color }\end{array}$ & 6 & 5 \\
\hline
\end{tabular}

Perhitungan Bahan Baku untuk Kemasan Obat

Berikut merupakan perhitungan persediaan biaya aktual dan juga biaya berdasarkan perhitungan economic order quantity pada produk kemasan obat dan shopping bag berdasarkan komponen bahan bakunya.

\section{Karton}

Berdasarkan perhitungan economic order quantity diperoleh total biaya persediaan aktual bahan baku untuk karton, yaitu:

$\left(\frac{60.000}{15.000} \times 13.500\right)+\left(\frac{15.000}{2} \times 50\right)$

$=$ Rp. $54.000+$ Rp. $375.000=$ Rp. 429.000

Perhitungan pemesanan EOQ untuk mengendalikan persediaan karton untuk memproduksi kemasan obat adalah :

$\mathrm{EOQ}=\sqrt{\frac{2 \times 60.000 \times 13.500}{50}}$

$=5.692$ lembar

Frekuensi pemesanan dengan jumlah ekonomis:

$\frac{D}{E O Q}=\frac{60.000}{5.692}=10 \mathrm{kali}$

Jadi, jumlah ekonomis dalam sekali pesan adalah 5.692 lembar dan jumlah pemesanan adalah 10 kali, maka total pemesanan sebesar 56.920 lembar.

\section{Safety Stock}

Standar deviasi $=70.200-54000$

$$
=16.200
$$

Maka besar dari standar deviasi pemakaian karton selama lead time 2 minggu adalah:

$$
\begin{aligned}
& \sigma \mu=\sqrt{l x(\sigma / 6)} \\
& =\sqrt{\frac{14}{30} x(16.200 / 6)} \\
& =1.844
\end{aligned}
$$

Jumlah persediaan pengaman dengan service level $95 \%$ dan $Z=1,65$ adalah:

$$
\begin{aligned}
& \mathrm{SS}=\mathrm{Z} \times \sigma \mu \\
& =1,65 \times 1.844 \\
& =3.043
\end{aligned}
$$

Jadi persediaan pengaman yang dibutuhkan PT X sebesar 3.043 lembar.

\section{ROP}

Maka titik pemesanan kembali dapat dihitung sebagai berikut:

$$
\begin{aligned}
\mathrm{ROP} & =\left(\mathrm{L} \times \mathrm{D}_{\mathrm{L}}\right)+\mathrm{SS} \\
& =(14 / 30 \times 60.000)+3.043 \\
& =31.043 / \mathrm{lembar}
\end{aligned}
$$

Jadi, jika persediaan karton di gudang telah mencapai jumlah 31.043 lembar (ROP), maka percetakan harus memesan sebanyak 56.920 lembar (EOQ). 
Maka total biaya persediaan bahan baku yang dikeluarkan PT $\mathrm{X}$ dengan diterapkannya metode EOQ adalah:

Total Cost $=\frac{60.000}{5.692} \times 13.500+\frac{5.692}{2} \times 50$

$=$ Rp. $142.305+$ Rp. $142.300=$ Rp. 284.605

\section{Tinta Black \& White}

Total biaya persediaan aktual tinta $\mathrm{B} \& \mathrm{~W}$, yaitu:

$\left(\frac{90}{23} \times 7.500\right)+\left(\frac{23}{2} \times 33.333\right)$

$=$ Rp. $30.000+$ Rp. 383.330

$=$ Rp. 413.330

Perhitungan jumlah ekonomis untuk tinta B\&W kemasan obat dapat dihitung sebagai berikut:

EOQ $=\sqrt{\frac{2 \times 90 \times 7.500}{33.333}}=6,3 \mathrm{~kg} /$ pesanan

Frekuensi pesan dengan perhitungan EOQ:

$$
\frac{90}{6,3}=14 \text { kali }
$$

Jadi, jumlah ekonomis dalam sekali pesan adalah $6,3 \mathrm{~kg}$ dan jumlah pemesanan dalam adalah 14 kali, maka total pemesanan sebesar 88 .

\section{Safety stock}

Standar defiasi $=105-81=24$

Standar defiasi dengan lead time 2 minggu:

$\sigma \mu=\sqrt{\operatorname{lx}(\sigma / 6)}$

$=\sqrt{\frac{14}{30} x\left(\frac{24}{6}\right)}$

$=3$

Jumlah defiasi dengan service level $95 \%$ dan $Z=1,65$

$\mathrm{SS}=1,65 \times 3=5$

Jadi perusahaan punya safety stock sebnyak $5 \mathrm{~kg}$

\section{ROP}

$\mathrm{R}^{*}=\left(\frac{14}{30} \times 90\right)+5=47$

Jadi, jika persediaan tinta $\mathrm{B} \& \mathrm{~W}$ di gudang telah mencapai titik $47 \mathrm{~kg}$ (ROP), maka perusahaan perlu memesan kembali sebanyak $88 \mathrm{~kg}$ (EOQ).

Maka jumlah biaya persediaan yang dikeluarkan PT $\mathrm{X}$ dengan diterapkannya metode EOQ adalah:

Total Cost $=\frac{90}{6,3} \times 7.500+\frac{6,3}{2} \times 33.333$
$=$ Rp. $107.143+$ Rp. 104.999

$=$ Rp. 212.142

\section{Tinta Full Color}

Total biaya persediaan aktual tinta full color, yaitu:

$\left(\frac{180}{26} \times 7.500\right)+\left(\frac{26}{2} \times 16.666\right)$

$=$ Rp. $52.500+$ Rp. $216.658=$ Rp. 269.158

Perhitungan jumlah ekonomis untuk tinta Full Color kemasan obat dapat dihitung sebagai berikut:

$\mathrm{EOQ}=\sqrt{\frac{2 \times 180 \times 7.500}{16.666}}=13 \mathrm{~kg} /$ pesanan

Frekuensi pesan dengan perhitungan EOQ:

$\frac{180}{13}=13$ kali

Jadi, jumlah pemesanan ekonomis dalam sekali pesan adalah $13 \mathrm{~kg}$ dan jumlah pemesanan dalam adalah $13 \mathrm{kali}$, maka total pemesanan sebesar $169 \mathrm{~kg}$.

\section{Safety stock}

Standar defiasi $=210-162=48$

Standar defiasi dengan lead time 2 minggu:

$\sigma \mu=\sqrt{l x}(\sigma / 6)$

$=\sqrt{\frac{14}{30} x\left(\frac{48}{6}\right)}$

$=5$

Jumlah defiasi dengan service level $95 \%$ dan $\mathrm{Z}=1,65$

$\mathrm{SS}=1,65 \times 5=9$

Jadi perusahaan punya safety stock tinta full color sebanyak $9 \mathrm{~kg}$.

\section{ROP}

$\mathrm{R}^{*}=\left(\frac{14}{30} \mathrm{x} 180\right)+9=93 \mathrm{~kg}$

Jadi, jika persediaan tinta full color di gudang telah mencapai titik $93 \mathrm{~kg}$ (ROP), maka perusahaan perlu memesan kembali sebanyak $169 \mathrm{~kg}$ (EOQ).

Maka jumlah biaya persediaan yang dikeluarkan Percetakan $\mathrm{X}$ dengan diterapkannya metode EOQ adalah:

Total Cost $=\frac{180}{13} \times 7.500+\frac{13}{2} \times 16.666$ =Rp. $103.846+$ Rp. $108.329=$ Rp. 212.175 


\section{Perhitungan bahan baku untuk Kemasan Obat}

\section{Kertas}

Berdasarkan perhitungan economic order quantity diperoleh total biaya persediaan aktual bahan baku untuk kertas, yaitu:

$$
\left(\frac{10.267}{3.422} \times 4.500\right)+\left(\frac{3.422}{2} \times 292\right)
$$$$
=\text { Rp. } 13.500+\text { Rp. } 499.612
$$

$=$ Rp. 513.112

Perhitungan jumlah ekonomis kertas sebagai bahan baku pembuatan shopping bag sebagai berikut:

$$
\begin{gathered}
\mathrm{EOQ}=\sqrt{\frac{2 \times 10.267 \times 4.500}{292}} \\
=563 \text { lembar /pesanan }
\end{gathered}
$$

Frekuensi pesan dengan perhitungan EOQ: $\frac{D}{E O Q}=\frac{10.267}{563}=18 \mathrm{kali}$

Jadi, jumlah ekonomis dalam sekali pesan adalah 563 lembar dan jumlah pemesanan dalam sebulan adalah 18 kali, maka total pemesanan sebesar 10.134 lembar dalam sebulan.

\section{Safety stock}

Jumlah pesedian pengaman bahan baku kertas sebgai berikut:

Standar deviasi $=10.800-9.600=1.200$

Maka besar dari standar deviasi pemakaian kertas selama lead time 2 minggu adalah:

$\sigma \mu=\sqrt{l x}(\sigma / 6)$

$=\sqrt{\frac{14}{30} x\left(\frac{1200}{6}\right)}$

$=137$

Jumlah persediaan pengaman dengan service level $95 \%$ dan $Z=1,65$ adalah:

$\mathrm{SS}=1,65 \times 137=225$ lembar

Jadi persediaan pengaman yang dibutuhkan Percetakan X sebesar 225 lembar.

\section{ROP}

Maka titik pemesanan kembali dapat dihitung sebagai berikut:

$\mathrm{ROP}=(14 / 30 \times 10.267)+225=5.017$

Jadi, jika persediaan kertas di gudang telah mencapai titik 5.017 lembar (ROP), maka perusahaan perlu memesan kertas kembali sebanyak 10.134 lembar (EOQ).
Maka jumlah biaya persediaan yang dikeluarkan PT $X$ dengan diterapkannya metode EOQ adalah:

Total Cost $=\frac{10.267}{563} \times 4.500+\frac{563}{2} \times 292$

$=$ Rp. $82.063+$ Rp. 82.198

$=$ Rp. 164.261

\section{Tinta B\&W}

Total biaya persediaan aktual tinta $\mathrm{B} \& \mathrm{~W}$, yaitu:

$\left(\frac{16}{8} \times 4.500\right)+\left(\frac{8}{2} \times 187.500\right)$

$=$ Rp. $9.000+$ Rp. 750.000

$=$ Rp. 759.000

Perhitungan jumlah pemesanan ekonomis untuk tinta $\mathrm{B} \& \mathrm{~W}$ shopping bag dapat dihitung sebagai berikut:

$\mathrm{EOQ}=\sqrt{\frac{2 \times 16 \times 4.500}{187.500}}=0,9 \mathrm{~kg} /$ pesanan

Frekuensi pesan dengan perhitungan EOQ:

$$
\frac{16}{0,9}=17 \text { kali }
$$

Jadi, jumlah pemesanan ekonomis dalam sekali pesan adalah $0,9 \mathrm{~kg}$ dan jumlah pemesanan adalah 17 kali, maka total pemesanan sebesar $15 \mathrm{~kg}$.

\section{Safety stock}

Standar defiasi $=17-16=1$

Standar defiasi dengan lead time 2 minggu:

$\sigma \mu=\sqrt{l x}(\sigma / 6)$

$=\sqrt{\frac{14}{30} x\left(\frac{1}{6}\right)}$

$=0,11$

Jumlah defiasi dengan service level $95 \%$ dan $\mathrm{Z}=1,65$

$\mathrm{SS}=1,65 \times 0,11=0,19$

Jadi perusahaan punya safety stock sebnyak $0,19 \mathrm{~kg}$

\section{ROP}

$\mathrm{R}^{*}=\left(\frac{14}{30} \mathrm{x} 16\right)+0,19=8$

Jadi, jika persediaantinta $\mathrm{B} \& \mathrm{~W}$ di gudang telah mencapai titik $8 \mathrm{~kg}$ (ROP), maka perusahaan perlu memesan kembali sebanyak $15 \mathrm{~kg}$ (EOQ).

Maka jumlah biaya persediaan yang dikeluarkan PT X dengan diterapkannya metode EOQ adalah: 
Total Cost $=\frac{16}{0.9} \times 4.500+\frac{0,9}{2} \times 187.500$ 164.375

$$
\text { = Rp. } 80.000+\text { Rp. } 84.375=\text { Rp. }
$$

\section{Tinta Full Color}

Total biaya persediaan aktual tinta full color, yaitu:

$\left(\frac{5}{5} \times 4.500\right)+\left(\frac{5}{2} \times 600.000\right)$

$=$ Rp. $4.500+$ Rp. 1.500 .000

$=$ Rp. 1.504 .500

Perhitungan jumlah ekonomis untuk tinta Full Color shopping bag dapat dihitung sebagai berikut:

$\mathrm{EOQ}=\sqrt{\frac{2 \times 5 \times 4.500}{600.000}}=0,3 \mathrm{~kg} /$ pesanan

Frekuensi pesan dengan perhitungan EOQ:

$\frac{5}{0,3}=16$ kali

Jadi, jumlah ekonomis dalam sekali pesan adalah $0,3 \mathrm{~kg}$ dan jumlah pemesanan dalam sebulan adalah 16 kali, maka total pemesanan sebesar $4 \mathrm{~kg}$ dalam sebulan.

\section{Safety stock}

Standar defiasi $=6-5=1$

Standar defiasi dengan lead time 2 minggu:

$\sigma \mu=\sqrt{l x(}(\sigma / 6)$

$=\sqrt{\frac{14}{30} x\left(\frac{1}{6}\right)}$

$=0,11$

Jumlah defiasi dengan service level $95 \%$ dan $Z=1,65$

$\mathrm{SS}=1,65 \times 0,11=0,19$

Jadi perusahaan memiliki safety stock sebanyak $0,19 \mathrm{~kg}$

\section{ROP}

$\mathrm{R}^{*}=\left(\frac{14}{30} \times 5\right)+0,19=3 \mathrm{~kg}$

Jika persediaantinta full color di gudang mencapai titik3 $\mathrm{kg}$ (ROP), maka perusahaan perlu memesan kembali sebanyak $4 \mathrm{~kg}$ (EOQ).

Maka jumlah biaya persediaan yang dikeluarkan PT $\mathrm{X}$ dengan diterapkannya metode EOQ adalah:
Total Cost $=\frac{5}{0,3} \times 4.500+\frac{0.3}{2} \times 600.000=$ Rp. $75.000+$ Rp. $90.000=$ Rp. 165.000

Persediaan bahan baku yang telah dihitung dengan menggunakan metode EOQ menghasilkan jumlah ekonomis. Berikut merupakan table penghematan biaya yang telah dihitung dengan menggunakan metode EOQ.

Tabel 2

\section{Hasil Penghematan Biaya Dengan Metode EOQ}

\begin{tabular}{|c|c|c|c|c|}
\hline & Bahan Baku & $\begin{array}{l}\text { Total Biaya } \\
\text { persediaan } \\
\text { aktual }(\mathrm{Rp})\end{array}$ & $\begin{array}{c}\text { Total Biaya } \\
\text { persediaan EOQ } \\
\text { (Rp) }\end{array}$ & Presentase (\%) \\
\hline \multirow{3}{*}{$\begin{array}{c}\text { Kemasan } \\
\text { Obat }\end{array}$} & Karton & 429.000 & 284.605 & 34 \\
\hline & Tinta B\&W & 413.330 & 212.142 & 49 \\
\hline & Tinta Full Color & 269.158 & 212.175 & 21 \\
\hline \multirow{3}{*}{ Shopping Bag } & Kertas & 513.112 & 164.261 & 68 \\
\hline & Tinta B\&W & 759.000 & 164.375 & 78 \\
\hline & Tinta Full Color & 1.504 .500 & 165.000 & 89 \\
\hline
\end{tabular}

\section{Simpulan dan Saran}

Dari hasil penelitian diatas, dapat disimpulkan bahwa proses produksi di PT X memiliki hasil yang baik. Karena seluruh pekerjaan saling berurutan dan dapat diselesaikan sesuai dengan jadwal yang telah disepakati. Dalam mengerjakan permintaan tersebut PT $\mathrm{X}$ memberikan waktu sisa 1-2 hari untuk mengecek ulang barang yang telah diproduksi sehingga bila terjadi kesalahan dapat segera diperbaiki.

Persediaan bahan baku yang dihitung dengan menggunakan metode EOQ dapat menghasilkan penghematan biaya dibandingkan dengan biaya aktual di perusahaan. Dengan menggunakan perhitungan EOQ perusahaan dapat mengetahui jumlah optimal yang dapat dipesan suatu bahan baku dalam periode tertentu dan biaya yang harus dikeluarkan. Perhitungan EOQ juga dapat membantu menekan biaya penyimpanan bahan baku. Dengan begitu biaya bahan baku dan penggunaannya dapat dikendalikan dengan 
sebaik mungkin. Jadi perusahaan tidak perlu menanggung kerugian akibat bahan baku yang dipesan terlalu banyak atau terlalu sedikit dan proses produksi pun dapat berjalan dengan lancar. Sehingga biaya bahan baku tidak menjadi beban perusahaan.

\section{Daftar Pustaka}

Assauri, S. (1993). Manajemen Produksi dan Operasi (edisi 4). Jakarta: Lembaga Penerbit Fakultas Ekonomi Universitas Indonesia).

Haming, M., \& Nurnajamuddin, M. (2012). Manajemen Produksi Modern Edisi 2 Buku 2. Jakarta: Bumi Aksara.

Heizer, J. B. (2010). Manajemen Operasi (edisi 9). Jakarta: Salemba Empat.

Hozo, S. P., Djulbegovic, B., \& Hozo, I. (2005). BMC Medical Research Methodology. Estimating the mean and variance from the median, range, and the size of a sample, 3 .
M'Arif, M. S. (2003). Manajemen Operasi. Jakarta : PT. Gramedia Widiasarana Indonesia).

Nasution, A. H. (2006). Manajemen Industri. Yogyakarta: Penerbit Andi.

Ristono, A. (2009). Manajemen Persediaan. Edisi Pertama. Yogyakarta: Graha Ilmu.

Sofyan, D. K. (2013). Perencanaan dan Pengendalian Produksi. Yogyakarta: Graha Ilmu.

Stevenson, W. J., \& Chuong, S. C. (2014). Manajemen Operasi: Prespektif ASIA Edisi 9 Buku 2. Jakarta: Salemba Empat.

Sudana, I. M. (2011). Manajemen Keuangan Perusahaan: Teori dan Praktik. Jakarta: Erlangga.

Syamsuddin, L. (2011). Manajemen Keuangan Perusahaan: Konsep Aplikasi dalam Perencanaan, Pengawasan, dan Pengambilan Keputusan. Jakarta: PT. Raja Grafindo Persada. 